\title{
Is Democracy Possible Without a Restriction of the Suffrage?
}

Vincenzo Alfano

Università degli Studi di Napoli "Federico II"

Napoli, Italia

\author{
e-mail:vincenzo.alfano@unina.it
}

\begin{abstract}
:
Today, the concept of democracy seems inextricably linked with that of universal suffrage. But is it true? To let that anyone with a given age has the right to vote is a very good democratic practice, or would prefer to question the criteria for access to this right, perhaps to develop new systems? The current crisis of democracy in the Western world is symptomatic of a detriment of the political consciousness of the people? And yet it is very likely to be admissible and that only from the mass, the large numbers, rises the better choices? In this paper I try to answer these questions, drawing from personal opinions and thoughts, which I hope will inspire questions and curiosity in those who, like me, believes that any system is always perfectible, and that its aim should be to that perfection, without fear of asking uncomfortable questions. Personally, in fact, I can accept democracy as "the worst form of government except all the others that have been tried", to quote a famous statement by Winston Churchill. But not for that I give up, and I try other ways. Ways that are more satisfying, more fair and keep us away from the horrors that only an angry mob can do.
\end{abstract}

Keywords: democracy, suffrage, universal suffrage, alternatives to universal suffrage, suffrage reduction

This paper was first published in a previous, different version in the Journal of Liberty and Society, vol. III, entitled "Democracy and Universal Suffrage: a necessary evil?".

Democracy: since it could not make what is right would be strong, it was done so that what was right is strong. Blaise Pascal

\section{What is Democracy?}

Democracy is a fleeting concept, and difficult to define. This word, indeed, hides a variety of levels for opinions, ideas so different from each other. Historically, in the embryo of the representative system that was the Athenian democracy, too often quoted in error, only one charge was out of the urn: the strategist or military magistrate. The other charges were determined by chance, the so-

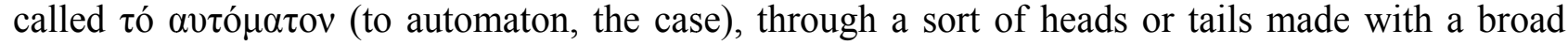
bean (cited in [1, p. 13]).

The term democracy is still ambiguous since its birth in the fifth-sixth century BC. In fact, the word $\delta \tilde{\eta} \mu \mathrm{s}$ (demos, people) lent itself to multiple interpretations. For the Greeks it could mean 
$\pi \lambda \tilde{\eta} \theta$ os (plethos, or the entire body of citizens), oi $\pi$ o $\lambda \lambda$ oí (hoi polloi, that is, an undefined "many"), oi $\pi \mathrm{o} \lambda \lambda \mathrm{ov \varepsilon ́ \varsigma}$ (hoi pollones, ie, more), or ö $\chi \lambda \mathrm{o} \varsigma$ (ochlos, ie the crowd) [2, pp. 5-6]. However, leaving aside for a moment this semantic problem (which is not so negligible as it is to decide who should exercise the power) as the real power belongs to those who exercise, how can the people not well defined, which is the owner of law, being awarded the right and power to exercise it? We know that the solution found by modern is representative democracy, or a representative transmission of the power.

But there is a big difference between the ancient democracy, and the so-called modern democracy: the first was in fact (at least in part) a direct exercise of power, the second is a way to limit it. The polis and the medieval communes had a short and turbulent life, but their political life resolved into a democracy without a state, in smalls towns established in a community. In Athens lived up to 35,000 people, and amongst them participated in meetings a minimum of 2,000 to a maximum of 5,000 people, according to our estimates. Only some of the decisions were actually taken by acclamation, and in any event, as well as it grown, the polis perished miserably, the intrinsic failure and inability to survive the expansion of space which established it and made it possible. When the term democracy emerged, after it was also vehemently rejected until the nineteenth century (remember a book written by Kant, who in 1795 criticized those who "had begun to confuse the republican constitution with the democratic one" noting that "the form democracy is necessarily a despotism" [4]), is in order to describe a totally different reality: our democracies are liberal-democracies, rich in mediation: the democracy of the ancient mind was a zero sum game, that translates into modern positive-sum decisions (compare [2, pp. 43-46]) In fact, if direct democracy of Athens were citizens (and as seen on the definition of citizens would be discussed, as that of the ancient Greeks had a long way from today, and not meant at all "the people" as we understand it today) to discuss and decide on at least some of the questions in the modern liberal democracy that is applied to the city, in a system that provides for the state (a concept that arises only in the fifteenth century with Machiavelli, and which has a long and troubled history, reaching affirm itself only in the nineteenth century, as stated in [2, p. 44]) and therefore has an area of infinitely greater and infinitely more complex problems, is to choose its representatives, acting on the issues.

In today's West, the word democracy seems to have now acquired the meaning which at least has the advantage of being more precise, of "majority rule". Indeed, in general, majority voting is seen as the means by which the people govern. Whether directly, even if minimally, such as choosing between different alternatives in a referendum, which most often indirectly, by choosing from time to time between the different candidates in an election. Despite this, however, even this simple definition has many problems ${ }^{1}$.

However, in conclusion, the non-semantic meaning and the difficulty (or perhaps impossibility?) in the real world to find a "real" democracy, have already been devoted to words and ink, and from very eminent scholars and intellectuals more qualified than me. Anyway, just because it is difficult to define precisely, democracy becomes a difficult concept to evaluate and criticize.

Representative democracy in fact does not qualify as a government of knowledge, but as a government of opinion, based on a common sentiment in the res publica. Representative democracy would be enough so that public opinion of the public. But, as noted in Homo Videns by Giovanni Sartori, this is not always true, as "the videocracy ${ }^{2}$ is manufacturing a massively hetero-directed review that apparently reinforces, but essentially empty, democracy as a government review", cf. [3, p. 46]). Or again, as Herstgaard says: "Opinion polls reign. Five hundred Americans are constantly being interviewed to tell us, that is two hundred and fifty million other Americans, what we think."

But at least you could agree that representative democracy aims to elect representatives as those that are most acceptable to the mass of the population. The systems with which the liberaldemocracy elects representatives (i.e. the electoral laws) and the concept of mass of the population 
(i.e. the elect), change from place to place, from a system to another and, occasionally, from an age to another.

\section{How Does the Democratic Process Work?}

The approval of the mass is, as manner of speaking, a leitmotif of democracy. But are we really sure that this is the best way to give shape to the executive and the legislative power? We are very

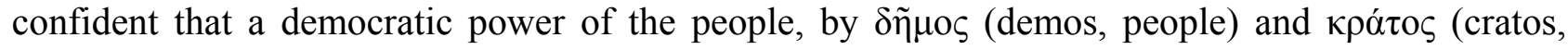

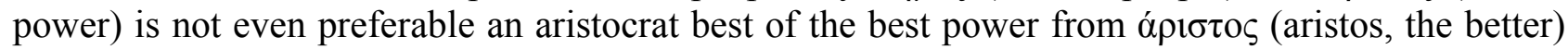

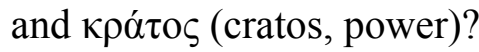

However, beyond such bold assumptions and the simple rhetorical questions, that democracy is certainly a delicate machine, a complex process that needs to run an infinite number of conditions: active citizenship, freedom of information, awareness of the importance of their vote and trust in institutions, to begin with. And even after free and transparent elections. Nowadays it seems that the major Western powers, where our concept of democracy is widely accepted, it has totally forgotten this lesson. So much so that never in recent years, our democratic system is experiencing an identity crisis, and suffering increasingly heavy bordered by theorists of new systems, that image will return to direct democracy through the power of new technologies, or the advent of technocracy. Anyway, in those states where the crisis is being felt, far from trying to solve it within itself, the democratic system tries to transplant to other countries, like an urn itself was enough to make a democratic state and a legitimate government. Maybe it calms the conscience to believe that our system should be exported, and relieves us from concerns about the perfectibility and that more and more we crawl inside (after all if you need to export it, implicitly means that the better).

Democracy is a long journey, complicated and full of pain and defeats. A system to succeed and to work needs to be heard, and to be desired. It needs people ready to fight to defend it. How can you pretend to take it and plant it in a country with a different culture? Above all, is it really feasible and desirable?

In modern Western democracies, the executive power is held by the body which guides the country toward a government program under which it was elected. It's clear that there is not a best program, and that different ideologies and different ideas are equally valuable and potentially, at least theoretically, right. But simplifying the ability and opportunity to practice a policy of right or left, would be better to choose the best representatives of all ideologies? Among those who can implement a program feasible, viable and to carry forward the country (or at least not send it to hell)? Among the most able candidates?

Similarly, the legislative power is given to the organ in charge of legislating to create laws. Wouldn't it be better in this role were to be elected the best, the more prepared and more able to create more useful policies for the community? It's clear that if these rhetorical questions were posed to anyone, the answer would be positive. But it is equally clear that an objection immediately arises: who does determines who are the bests? Through what criteria?

\section{A Brief History of Universal Suffrage}

The principle of universal suffrage is related to the ideas of the general will and political representation brought by Jean-Jacques Rousseau (1712-1778) in 1762 in his work The Social Contract. Based on these principles, we draw our assumption according to which political representation is standing in its own free will. The citizens in modern democratic states are the basis of the political system and universal suffrage is the elected legislative body of a State in the presidential republics, this is also for the election of the Head of State. The principle of universal male suffrage was introduced for the first time in the United States of America from their independence in 1776, but it was fully applied, however, with various restrictions based on wealth 
and education, only in 1966 by two judgments of the Court Supreme. It is generally considered the date of 1893, in which New Zealand introduced universal suffrage, and male and female, as the first state in the world. In France in 1792, after the French Revolution, the Government introduced universal suffrage, but only for a short period of time. Only since 1946 in fact universal suffrage will be effective and stable. Europe moved in this direction during the nineteenth century: from a restricted suffrage - for the most part attributed to a portion of the population census or on the basis of education - passed gradually to universal suffrage. And throughout the nineteenth century the issue of universal suffrage will debated by various intellectuals, lined up on opposite sides. Alexis de Tocqueville (1805-1859), moderate aristocrat, though elected with a landslide victory (110,704 votes out of 120,000 ) was very critical towards this issue, stating in his memoirs that "there have been more ferocious than those of the revolutionaries of 1848, but I do not think there have been more foolish. They did not know or use of universal suffrage, or do without" (cf. [7, p. 385]). The progressive and feminist George Sand (pseudonym of Aurore Lucile Dupin Amantino, 1804-1876) instead wrote to Giuseppe Mazzini (1805-1872) in 1848: "We must recognize powerless in the face of this inevitability of a new political order in history: the suffrage Universal" (cf. [1, p. 29]). The same Sand wrote in 1869 to Gustave Flaubert (1821-1880) about the extended vote to all citizens "is just as stupid of divine law, though a bit "less odious"'(cf. [8, pp. 577-578], translated by the author). Who, years later, in 1870, replied: "Dear George, respect, fetishism that they all have universal suffrage for me the most sick of papal infallibility. But do you really believe that if instead of being ruled by the French crowd was in the hands of the mandarins would be the point of chaos and doom in which we are?" (cf. [1, p. 29]).

Finally, it also recalls the situation in the Italian peninsula, only the Grand Duchy of Tuscany in 1848 granted limited suffrage for men and women. The first and only State which granted universal suffrage, then, though limited to the propertied classes. Among the very first to speak, in Italy, there Ippolito Nievo (1831-1861), which in a little-known essay, Political revolution and the national revolution, of 1859 , criticize the distinction between the intellectuals and "the vast majority of the nation's illiterate, the rural populace": for Nievo the Risorgimento is a political revolution that has become a national revolution, establishing a system of representation based on the general universal suffrage (cf. [5, p. 63]). "Without that it will never be neither safe nor sustainable," writes Nievo. Among the supporters of direct universal suffrage, there is Carlo Cattaneo (1801-1869), who supports it, "excluding all the subterfuges that were invented by the forgers of the public vote." However, the same Cattaneo declares himself aware, with great foresight, that "universal suffrage is not a magic wand that can protect people from the momentary mistake." For Cattaneo science have to foster the policy and culture have to form the citizens (cf. [9, p. 100]).

The principle of universal suffrage was established, therefore, at least in Europe, in an era very different from today, where the historic cultural supremacy of the aristocracy was rightly questioned by the sale of patents of nobility and the rise of a class cultured medium that, once again rightly, wanted representation and voice on the choices of government.

The application was, inter alia, by no means fast: New Zealand in 1893 as the first country in the world, in Australia in 1902, in Finland in 1906, in Norway in 1913, in Denmark in 1917, Sweden in 1917 as in Russia, following the Russian revolution, the United Kingdom and Ireland in 1918, Germany in 1919, partly in Belgium in 1919, fully only in 1948, Canada in 1920, Turkey in 1923, in Ecuador partially in 1861, fully in 1924 in South Africa in 1930, Spain in 1931, Brazil and Uruguay in 1932, Cuba in 1934, India in 1935, Japan and France (after a brief period in 1792 to Following the revolution) in 1946, Argentina in 1947, Israel in 1948, Indonesia in 1949, in San Marino in 1958 in Switzerland, recognized the right to vote to women until 1971, Portugal has come full universal suffrage only in 1974. And yet, there is no universal suffrage in various countries, including Hong Kong, Lebanon, Brunei, Saudi Arabia, the UAE and, very special case, that I add just for the sake of completeness, Vatican City. 
So, what now seems to us an innate right, natural and necessary, and the only way possible is actually very recent history. And then, as the philosopher Michel de Montaigne Eyquem (15331592), "nature call our beliefs". Natural rights are changing: for Aristotle, slaves were natural, and women naturally inferior. It is also, incidentally, a system already in crisis, after less than a century of effective implementation in much of the world. Do we really believe that universal suffrage is actually a step forward? An achievement of civilization? Or are we simply desperately attaching a system that does not work just because we feel familiar with it?

\section{Democracy and New Media}

With the advent of the internet and of the new information and communication technologies in general, with the reduction of the personal privacy of anyone but especially of public personalities, and the reduction of opportunity to "get away" by politicians and public figures, long short story, in a world where seems possible to know everything about everyone at any time, it's really still so important the influence of politicians on voters who are not particularly prepared over the topic? Their ability to influence the vote hiding the truth? In today's world, the spread of technologies that enable a more efficient and (more importantly) a much faster communication, has essentially two possible important effects on democracy. On the one hand, costs well highlighted by the theory of rational ignorance of the non-voting by Anthony Downs [10] (which, oversimplifying, in shorts define as rational for an elector to consider too expensive to inquire about who best suits his interested and so who he should vote to protect them, in relation to the real influence that his single vote can have on the outcome of the elections) can be assumed as greatly lowered. Indeed, with well spread and easy access to the web, and the vast amount of information available there, it would be reasonable to expect that today is much easier and faster than once to inquire about the various candidates and their programs, as well as to be aware of the actual capacity to pursue them or of their chances of winning.

On the other hand, if objectively the amount of information available to anyone is huge and easily accessible, and it's immeasurably superior in terms of plurality of voices and news update than what was available just a bunch of years ago, the average quality of them is very questionable. It is increasingly difficult to understand the real reliability of a source over the new ICT. The Internet provides anyone with a smartphone gigabytes of data on any public personality (or alleged). But how many of those data are really reliable? How much is it really possible to discern between a fanatic that post fictional news from his room, and a competent journalist who works hard on the field? Unfortunately, I suspect that the fast diffusion of blogs and social media, and subsequent use of these also to make information, has created a impoverishment of "professional" information.

Probably also to follow the trends and needs of the market, seems to me that professional of the information world are chasing the lower standards (at least generically, as a trend), and apparently are no longer interested in providing information that stands out in quality. And that's (maybe) harder to be found interested in the customers. Probably, the enormous changes that have distorted the daily lives of all of us in such a short time, have not yet been fully digested by the information business. Which today offers to the market essentially two things: either a model that is still strongly anchored to tradition, with all the limitations of the case, or alternatively, a heavily deflected version of the news pushed towards entertainment, with content closer and closer to the two-faced monster called "infotainment". All this, in fact, does not make politicians more transparent and bare to the eyes of their constituents than they were fifty years ago. It's a matter of fact that today a photo stolen by a curious commoner with his mobile phone can go around the world in just a few minutes (seconds?), thing which would hardly have been possible just twenty years ago. But every single hour of every single day are stolen so many photos that the white noise becomes so high that becomes very difficult for any user to divide what is really interesting for him from what is not. And so anybody end up relying on sources that are deemed reliable person, who 
may, to stay in the example, not mention this famous photo stolen. And that newspaper, perhaps, have special interests to present specific points of view, with all due respect to freedom of information and unfiltered promise and promoted from the web.

Also, as I said, the line between a newspaper and a blog is every day more and more tenuous, as it is becoming the one between information and entertainment. This does nothing more than make political advantage in the market in terms of electoral palatability those men who know how to use these media, or who surround themselves with experts who are able to do it for them. But on the other hand, this aspect is very different from the cultural revolution in the fifties saw the triumph of politicians more aesthetically pleasing to the advent of the debates aired on television rather than on the radio? The years passes, the media changes, and the skills necessary to dominate them and to reach popular consensus with them. But the fact remains that the average voter, originally fascinated by a beautiful voice, then by a nice-looking person, today is charmed by a person capable of being effectively placed on the web. None of these three capacities is intrinsically desirable, is better than the other two, or makes a politician cleverer or smarter than someone who does not have that ability. At least certainly not more than is desirable to elect politicians with the technical ability to carry out its program in its mandate.

\section{Let everyone vote is truly democratic?}

The so-called democracy (and I use the word called to underscore the fact that as already widely discussed; it is difficult to arrive to a clear definition of the term) is in crisis. And on this matter, I think we need to spend very few words: anyway we means this ambiguous word, indeed, there is no doubt that in the West we are experiencing a crisis of the democratic system. A crisis which, in my humble opinion, is mainly explained by one fact: the lack of awareness among people of the importance of their role in the operation of the system. Democracy is a delicate wheel, which provides for the operation of the sincere and conscious participation of the voters. Without this, it is impossible to talk about democracy if you do not feel belonging to the community, and you are not aware of the importance of their vote, you are not part of the demos, and then accepting the vote of that's everyone goes beyond the concept of democracy. And it's indeed harmful to the system.

And, I wonder, in how many cases today there is this awareness? Where do they feel the need to inform themselves and do well to ponder their choice in the urn? The logics that currently lead to vote are quite different. And I am not thinking only to the exchange vote, although paradoxically unethical in a democratic system could be considered legitimate and easily return to the voter in expanding the concept of "care of their interests." I am thinking especially to the masses instead of neo-teens who vote out of sympathy or approval, to the many disillusioned policy they choose the least bad of a nose, and just to those who believe that "so are all the same" and vote purely by chance. Or even in our country, to people who unfortunately do not have full use of his mental faculties, but which have been permitted to vote. Or finally the enormous masses, worse than all others, think they know. Voters who, in my opinion, now represent the majority percentage of the electorate, or at least dangerously close to half a slice. Fernando Savater writes: "Freedom is deciding, well, do not forget, realize that you're deciding" [6]. And how many realize it today?

John Searle has worked [11] at the beginning of his career, on the speech act theory, and in particular, for our interests, on what his master John Langshaw Austin called illocutionary acts. Illucutionary acts are acts of language which consist in saying something ${ }^{3}$. Beyond the locution, indeed, for Searle every speech act has an illocution, which can be accepted or not by the other part involved in the communication. This is very related to my point: in fact between two politician, at constant expressions, and with this I mean expressing the same concept, the same program, is the most able at managing illocution to get the best perlocutions. Or, in other words, also a good politician with a good program and useful skills to implement it, will not go far if he does not choose carefully the illocutions, maybe relying on a pro. Exaggerating (but perhaps, unfortunately, not too much), is the politician with the best illocutions to obtain the support of the electorate. 
Indeed, if any form of communication is influenced by illocution and perlocution, as Searle speech acts theory states, the problem of democracy that we have examined is just a specific case of a problem inherent in every human interaction. Indeed, any information we, as human being, receive, is implemented through an illocution, and thus interpreted: this generates a perlocution from the receiver, and not just a "sterile" reaction at the information transposed.

The original concept of democracy is then meaningless for us so that you come to "impose" the vote in certain foreign countries. Countries in which the model, the Western culture of democracy, has never existed. With catastrophic results, among other things are easy to predict. If here, where it was born in the West, the Democratic machine sends dangerous signals of crisis and his wheel does not rotate any more, how can we expect it works where free information and awareness of the importance of voting is a mere illusion? Where centuries of trial and democratic culture have been explained to the masses, living a crisis for a disastrous war, in a few minutes from a stranger, who told everyone how beautiful and important is to put an $\mathrm{X}$ on a sheet? Surely democracy is not exportable practice, and most likely the West today exports it to hide their crises, and to feel a clear conscience. On the other hand, if there is need to export it, implicitly means that the democratic system is still the best.

However, for the same reasons that democracy is not exportable, in my opinion you cannot expect that it works now even with us. You cannot expect that a representative government chosen by people, is invested by the actual voters, who mostly have no real awareness and knowledge of exactly what they're doing. Just as it is happening in the West.

In addition, in my opinion it is absurd to claim that the mass choose the best. In addition to be representative, a government should be efficient and effective, and should work for the implementation of a program. In Italy, today, the confidence of Parliament to the Government (I remember once again that, although there is sometimes forgotten, until proven otherwise, we live in a Parliamentary Republic and the Prime Minister is elected by the people, but as long as he governs he has the confidence of Parliament), has expressed confidence about the program, and not the executive.

But how can the people, disinterested and uninformed, choose the best program? And how could the mass, even if the public were an interested and an informed one, (which, as I said, probably is not) opt for the very best choice? I will be objected that there is no choice at all. And this is true: politics is largely of visions and ideas, all lawful and no absolute best. But how can we hope that the synthesis of the choice of all out the best? It may be objected that the vote is a right, and that universal suffrage is one of the greatest achievements of modern civilians. In my opinion it is not, or rather, it probably was but now no longer is.

I will also tell you that the public, are generally poorly informed and interested in politics, in an electoral democracy does not decide issues, but chooses those who will decide, thus passing the buck by the electorate to elect, from demos to his representatives (cf. [2, p. 21]). But how can people not informed, or who will be selected to assess the best way to decide the issues? We must however have a responsibility to choose: there is for competent people and trust for advice about which specialist to contact? Maybe we do not go to a doctor that we trust to ask what is the best specialist in the square?

What should I think today is a potentially universal suffrage. That would really be a civil achievement. In fact, virtually every person shall have the right to vote, but to realize this potential the city itself must demonstrate an understanding of what it means to vote. Be careful, this does not mean that we should go to investigate, or even worse, to review the political and ideological ideas of a citizen (in this case in fact you would have at best a dangerous illiberal regime), or that only those who have a certain degree can vote (in which case there might be incurred in the dangerous problem of the culture of authoritarianism, and by the way you invest schools or universities are powers that are not at all suited to manage) or that the city should be responsible for knowing the codes of case law in detail as much as a magistrate. It s simply required that a national voter should have the most basic concepts of civic and political education to enable them to be aware of the 
outcomes that their vote will help determine. For example, what is the difference between a presidential republic, a parliamentary and federal one? Among the Upper House and Lower House? What are the powers of the Presidency of the Council of Ministers and the Presidency of the Republic? What is the difference between a decree-law and a bill? What is the process of approving a law? What is a Parliamentary Committee? What is the difference between proportional representation method, majority and mixed? What is the difference between a party and a civic list? What is a minimum threshold? What is the difference in assigning a majority of the premium (and what it is, and how to determine) the majority coalition or majority-List? In fact, for example, vote for the list $\mathrm{X}$ with a proportional representation method can determine the outcome is completely different from those who would vote for the same list $\mathrm{X}$ by a method the majority, and the citizen has a duty to be aware of this, if to have the right to participate in the political life of a country.

\section{References:}

1. Ajello, Mario, Storie di Voto. Donzelli editore, 2006.

2. Sartori, Giovanni, La democrazia in trenta lezioni. Mondadori, 2008.

3. Sartori, Giovanni, Homo Videns. Editori Laterza. 1997.

4. Kant, Immanuel, Zum ewigen Frieden. 1795.

5. Cerroni, Umberto, Il pensiero politico italiano. Newton Compton, 1995.

6. Savater, Fernando, Etica per un figlio. Laterza, Bari, 1992.

7. Alexis de Tocqueville, Ricordi (in Scritti Politici, vol. I, Utet, 1969).

8.George Sand letter, August the 3rd, 1870 (in Euvres complètes de Gustave Flaubert, vol. 14 [Correspondance 1859-1871], Club de l'Honnéte homme, 1975).

9. Nievo, Ippolito, Rivoluzione politica e rivoluzione nazionale. Udine: Istituto editoriale veneto friulano, 1994.

10. Downs, Anthony, An Economic Theory of Democracy. New York: Harper \& Row, 1957.

11. Searle, John, Speech Acts. An Essay in the Philosophy of Language. Cambridge:

Cambridge University press, 1969.

\section{Notes}

1. That things are not so simple is shown by the paradox of the 2000 election, in which a country like the United States, which is considered the most democratic in the world, elected to the presidency a candidate like George W. Bush, who had received a number of votes less than his opponent Al Gore.

2. According to Sartori, in our society now reigns sovereign primacy of the image: the visible prevails on intelligible, and the ability to abstract, to understand and therefore to distinguish between true and false is now atrophied. According to the eminent political scientist, this chilling reality has a unique and seemingly unexpected creator: television. It destroys more knowledge than it produces. And destroys even the human symbolic capacity, the process by which humans communicate articulating sounds and signs of "significant", and getting closer to the animal. This is not progress, but just the opposite. Professor says: "Knowing imaging is not democratic, as many say knowing through images-culture does not spread, it erodes the foundations. Television homogenizes the customs and fashions, but at the same time, it locked up in small villages in conflict. The amount crushing more and more quality. And for a moment if we delude ourselves to be free citizens in a free market, we have perhaps forgotten that we are not TV customers, but companies who buy space advertising".

3. According to the speech act theory, every speech act consists of three parts: locution (i.e., the structure and the wording), illocution (i.e. the target, the communicative intention) and perlocution (i.e. the effect of the linguistic act on the interlocutor). 